\title{
Deep crustal structure around the Atotsugawa fault system, central Japan: A weak zone below the seismogenic zone and its role in earthquake generation
}

\author{
Junichi Nakajima ${ }^{1}$, Aitaro Kato ${ }^{2}$, Takaya Iwasaki ${ }^{2}$, Shiro Ohmi ${ }^{3}$, Tomomi Okada ${ }^{1}$, Tetsuya Takeda ${ }^{4}$, \\ and The Japanese University Group of the Joint Seismic Observations at NKTZ \\ ${ }^{1}$ Research Center for Prediction of Earthquakes and Volcanic Eruptions, Graduate School of Science, \\ Tohoku University, Sendai, Japan \\ ${ }^{2}$ Earthquake Research Institute, University of Tokyo, Tokyo, Japan \\ ${ }^{3}$ Disaster Prevention Research Institute, Kyoto University, Uji, Japan \\ ${ }^{4}$ National Research Institute for Earth Science and Disaster Prevention, Tsukuba, Japan
}

(Received July 7, 2009; Revised May 24, 2010; Accepted June 25, 2010; Online published August 31, 2010)

\begin{abstract}
We carried out travel-time tomography around the Atotsugawa fault in central Japan, using arrival-time data obtained from a dense temporary seismograph network in joint observations by the Japanese University group. The observed velocities beneath the fault are 10-13\% lower than those of the assumed host rocks (pyroxene amphibolite and hornblende-pyroxene gabbro) in the lower crust. Because the seismogenic layer is thickest in the central part of the fault, reaching a depth of $\sim 15 \mathrm{~km}$, we infer that the low-velocity anomaly is caused by aqueous uids. Fluid fractions in the lower crust are estimated to be $2-3 \%$ and $\sim 10 \%$, assuming pyroxene amphibolite and hornblende-pyroxene gabbro, respectively. A distinct low-velocity anomaly is imaged in the central part of the Atotsugawa fault at a depth of $10 \mathrm{~km}$, where seismic activity is very low at the upper $7 \mathrm{~km}$ and creeplike movement is observed at the surface. This anomaly is horizontally isolated but vertically connected to the lowvelocity anomaly in the lower crust. We interpreted that abundant aqueous uids supplied from the lower crust are responsible for this anomaly. High pore uid pressure may enhance the stability of frictional slip, resulting in aseismic or episodic slip along the fault.
\end{abstract}

Key words: Seismic tomography, aqueous uids, lower crust, fault creeping.

\section{Introduction}

The Atotsugawa fault system, in the northern part of central Japan, is composed of three subparallel right-lateral strike-slip faults: the Atotsugawa, Ushikubi, and MozumiSukenobu faults (Fig. 1(b)). This system is one of the most active fault systems in Japan. The Atotsugawa fault has the highest seismicity of the three faults, and its seismicity varies along the fault (Mikumo et al., 1988; Ito et al., 2007; Wada et al., 2007). Seismicity in the central part of the Atotsugawa fault is deeper than on its western and eastern parts, extending to $\sim 15 \mathrm{~km}$ depth, and is very low in the upper $7 \mathrm{~km}$ of the central part (Fig. 1(c)). On the basis of this seismic pattern, we divide the Atotsugawa fault into eastern, central, and western sections as shown in Fig. 1(c).

The recurrence interval of large earthquakes along the Atotsugawa fault system is estimated to be 2,500 years (Takeuchi et al., 2003). In 1858, the Hietsu earthquake ( $\sim M 7$ ) occurred along the Atotsugawa and MozumiSukenobu faults. Repeated electronic distance measurement observations on short baselines across the fault have detected creeplike movement of $1.5 \mathrm{~mm} / \mathrm{yr}$ in the cen-

Copyright (C) The Society of Geomagnetism and Earth, Planetary and Space Sciences (SGEPSS); The Seismological Society of Japan; The Volcanological Society of Japan; The Geodetic Society of Japan; The Japanese Society for Planetary Sciences; TERRAPUB.

doi:10.5047/eps.2010.06.007 tral section of the Atotsugawa fault (Geographical Survey Institute, 1997), where seismic activity is very low in the upper $7 \mathrm{~km}$. Hirahara et al. (2003) also suggested the possibility of creeplike movement in the central section using an across-fault GPS array.

The Atotsugawa fault system is located in a zone of high strain rate, identi ed by GPS observations (Sagiya et al., 2000), called the Niigata-Kobe Tectonic Zone (NKTZ) (Fig. 1(a)). The NKTZ, which is $\sim 500 \mathrm{~km}$ long in the NESW direction and $\sim 100 \mathrm{~km}$ wide, undergoes contraction in the WNW-ESE direction at a rate several times greater than in surrounding regions. The observed horizontal displacement rates in the NKTZ have been discussed in terms of interplate deformation (e.g., Shimazaki and Zhao, 2000) and intraplate deformation (e.g., Iio et al., 2002; Yamasaki and Seno, 2005). Nakajima and Hasegawa (2007a) described a low-velocity zone in the lower crust along the NKTZ, and suggested that anelastic deformation in the lower crust contributes to the large contraction at the surface. Jin and Aki (2005) reported that a low- $Q$ zone appears beneath the NKTZ at frequency bands of 1-2 and 2-4 Hz.

To elucidate the structures around the Atotsugawa fault system with high accuracy, which is key to understanding the physical mechanisms of stress accumulation along an earthquake fault, the Japanese University group conducted joint seismic observations for ve years, begin- 

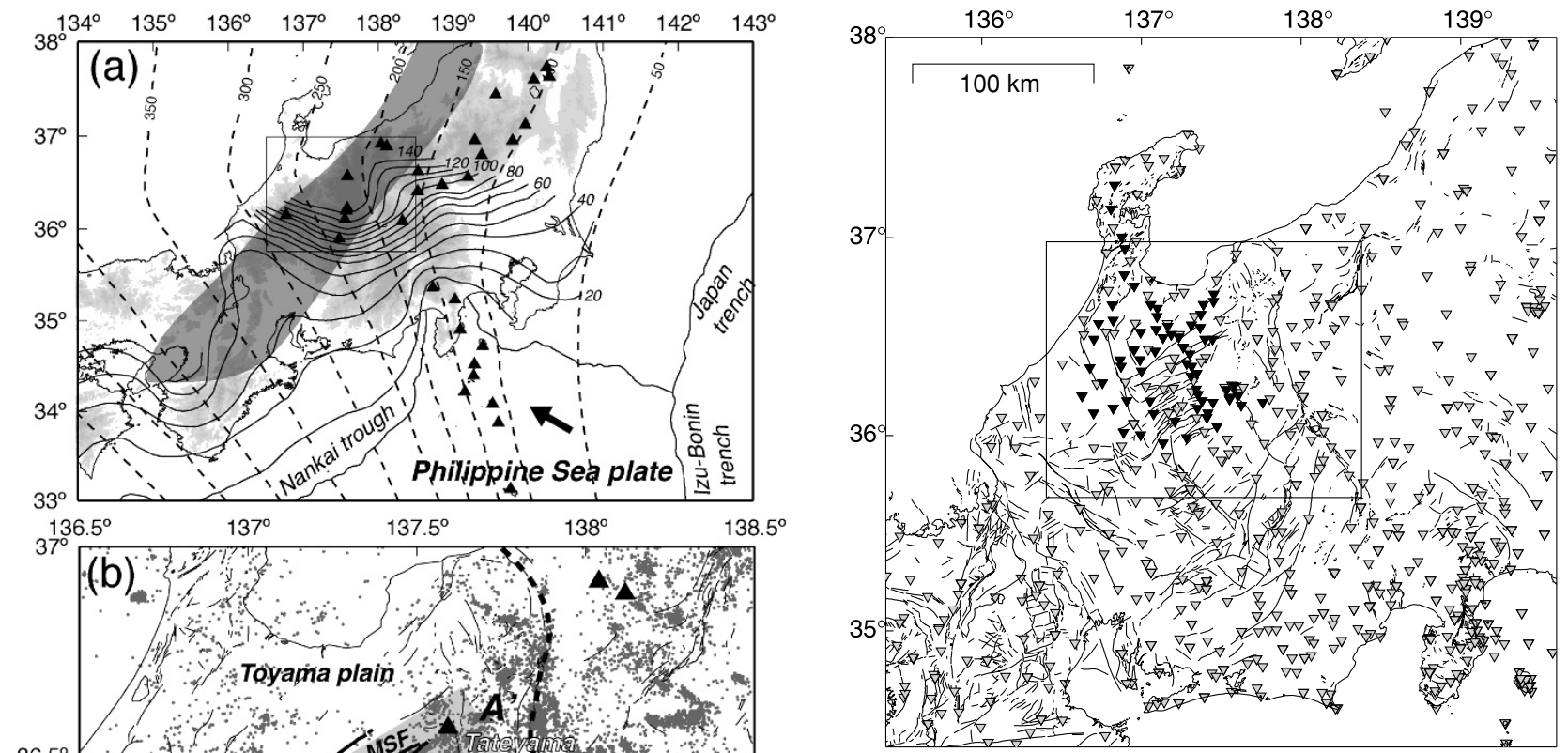

Fig. 2. Distribution of seismic stations used in this study. Gray triangles denote stations in the nationwide seismograph network, and black ones are temporary stations installed by the Japanese Universities (The Japanese University Group of the Joint Seismic Observations at NKTZ, 2005). The rectangle represents the inversion area.

nationwide seismograph network to obtain a detailed seismic velocity structure of the crust and uppermost mantle around the Atotsugawa fault system. This paper explores the relationship between structural heterogeneity, seismic activity, and geodetic movement, then discusses a possible strain-accumulation process for the Atotsugawa fault.

\section{Data and Methods}

The arrival-time data used in this study consisted of three

Fig. 1. (a) Tectonic setting around the study area. Depth contours of the Pacific (Nakajima et al., 2009) and Philippine Sea slabs (Hirose et al., 2007, 2008; Nakajima et al., 2009) are shown by dashed and solid lines, respectively. Black triangles denote active volcanoes. The plate motion of the Philippine Sea slab relative to the Eurasia plate is indicated by a black arrow (Seno et al., 1993). The Niigata-Kobe Tectonic Zone (Sagiya et al., 2000) is shown in gray shading. The black rectangle denotes the study area, which is magnified in (b). (b) Distribution of seismicity occurring from 2002 to 2007 at depth $<40 \mathrm{~km}$ (gray dots) and active faults (thin lines). The three major faults forming the Atotsugawa fault system, the Atotsugawa (AGF), Mozumi-Sukenobu (MSF), and Ushikubi (UKF) faults, are indicated by thick black lines. Earthquakes in the gray area $\left(\mathrm{A}-\mathrm{A}^{\prime}\right)$ are also shown in (c). (c) Cross-sectional view of seismicity around the Atotsugawa fault system. The dashed line denotes the approximate depth limit of earthquakes. An area of low seismicity in the central section is shown in gray. The Atotsugawa fault is divided into eastern, central, and western sections on the basis of seismicity distribution.

ning in 2004 (The Japanese University Group of the Joint Seismic Observations at NKTZ, 2005). The seismic network consisted of 63 stations with telemetry systems and 10 stations with off-line portable recorders, covering an area of $100 \times 100 \mathrm{~km}$ (Fig. 2). The network provided a station separation of $\sim 10 \mathrm{~km}$ around the fault, which is half that of the permanent nationwide seismograph network in Japan.

We apply travel-time tomography to the high-quality arrival-time data recorded by the temporary network and the seismic observations by the Japanese University group From this data set we selected earthquakes of $M>2.0$ from May 2005 to July 2007 that satisfied the condition $H_{\text {dep }}>D_{\text {min }}$, where $H_{\text {dep }}$ is the depth of the earthquake and $D_{\min }$ is the epicentral distance to the nearest station with $P$ - and $S$-wave arrival picks. This criterion kept earthquakes whose focal depth was well constrained. We then divided the study area into $0.02^{\circ} \times 0.02^{\circ} \times 2 \mathrm{~km}$ blocks and selected the single earthquake in each block with the largest number of observations, which yielded a uniform distribution of earthquakes. In this manner, we obtained 811 earthquakes (circles in Fig. 3). Arrival times for these events were manually picked from seismograms at the temporary and permanent stations in the study area. Permanent stations have been maintained by the National Research Institute for Earth Science and Disaster Prevention, Tohoku University, University of Tokyo, Nagoya University, Kyoto University, National Institute of Advanced Industrial Science and Technology, the Tokyo Metropolitan Government, the Shizuoka Prefectural Government, the Kanagawa Prefectural Government, the City of Yokohama, the Japan Marine Science and Technology Center, and the Japan Meteorological Agency. The second data set was the arrival-time data for 601 earth- 


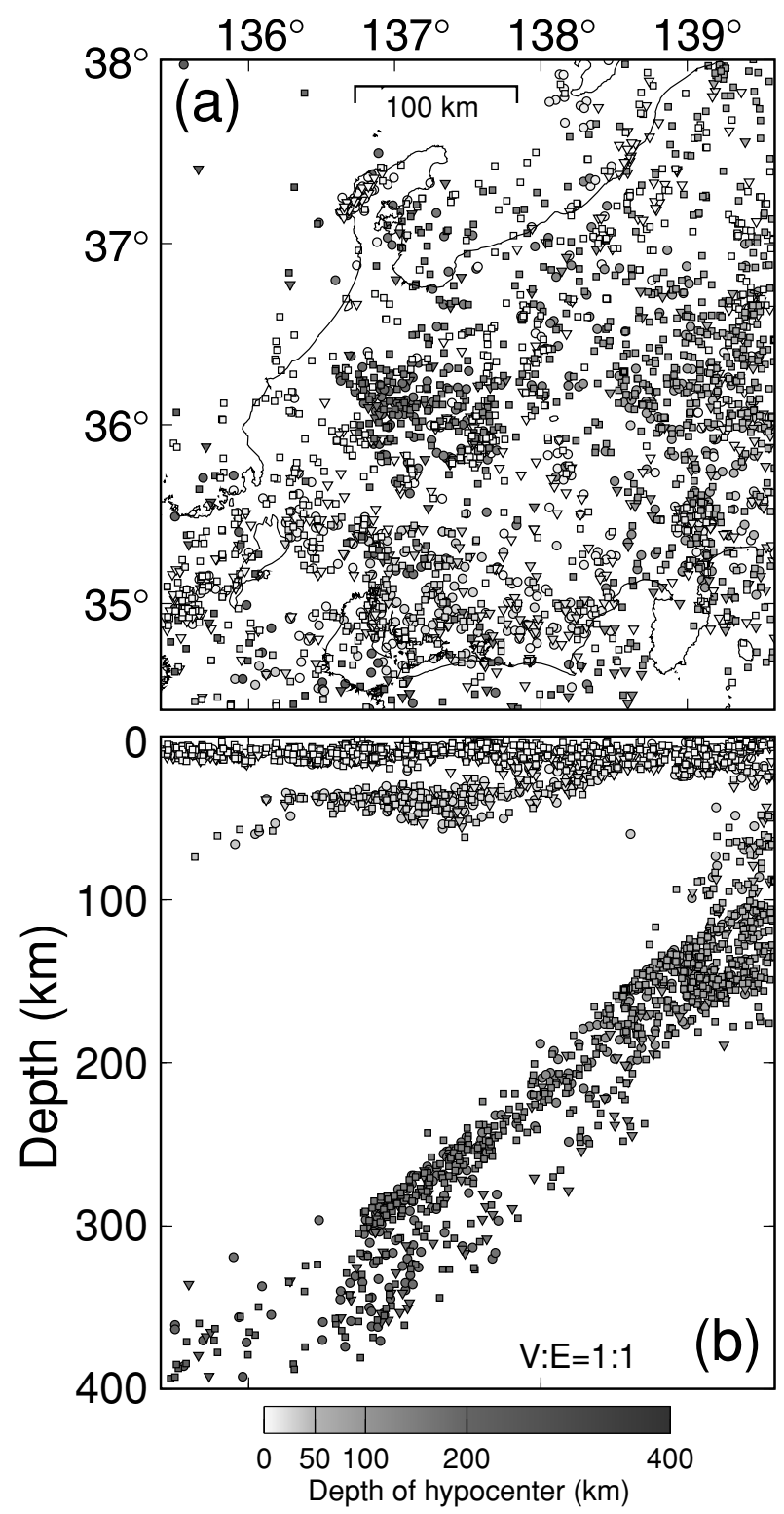

Fig. 3. (a) Map view and (b) cross-sectional view of distribution of earthquakes used in this study. The gray scale represents the focal depth of earthquakes. Circles denote 811 earthquakes occurring during the period of temporary observations from May 2005 to July 2007. Triangles represent 601 earthquakes that occurred from August 2007 to May 2008, and squares denote 1,541 earthquakes included in Nakajima and Hasegawa (2007a).

quakes that occurred from August 2007 to May 2008 (triangles in Fig. 3). The third data set was derived from the arrival-time data for 1,541 earthquakes from January 2001 to April 2005 (squares in Fig. 3). The third data set was used by Nakajima and Hasegawa (2007a) and was useful for constraining velocity structures over a wider region around the study area. The latter two data sets were produced at Tohoku University and involved only the permanent stations. All earthquakes were relocated prior to the inversion using the 3D velocity model of Nakajima and Hasegawa (2007a). The total number of stations used in this study was 535 (Fig. 2).

The tomographic method of Zhao et al. (1992a) was applied to the arrival-time data to determine 3D $P$ - and $S$ -
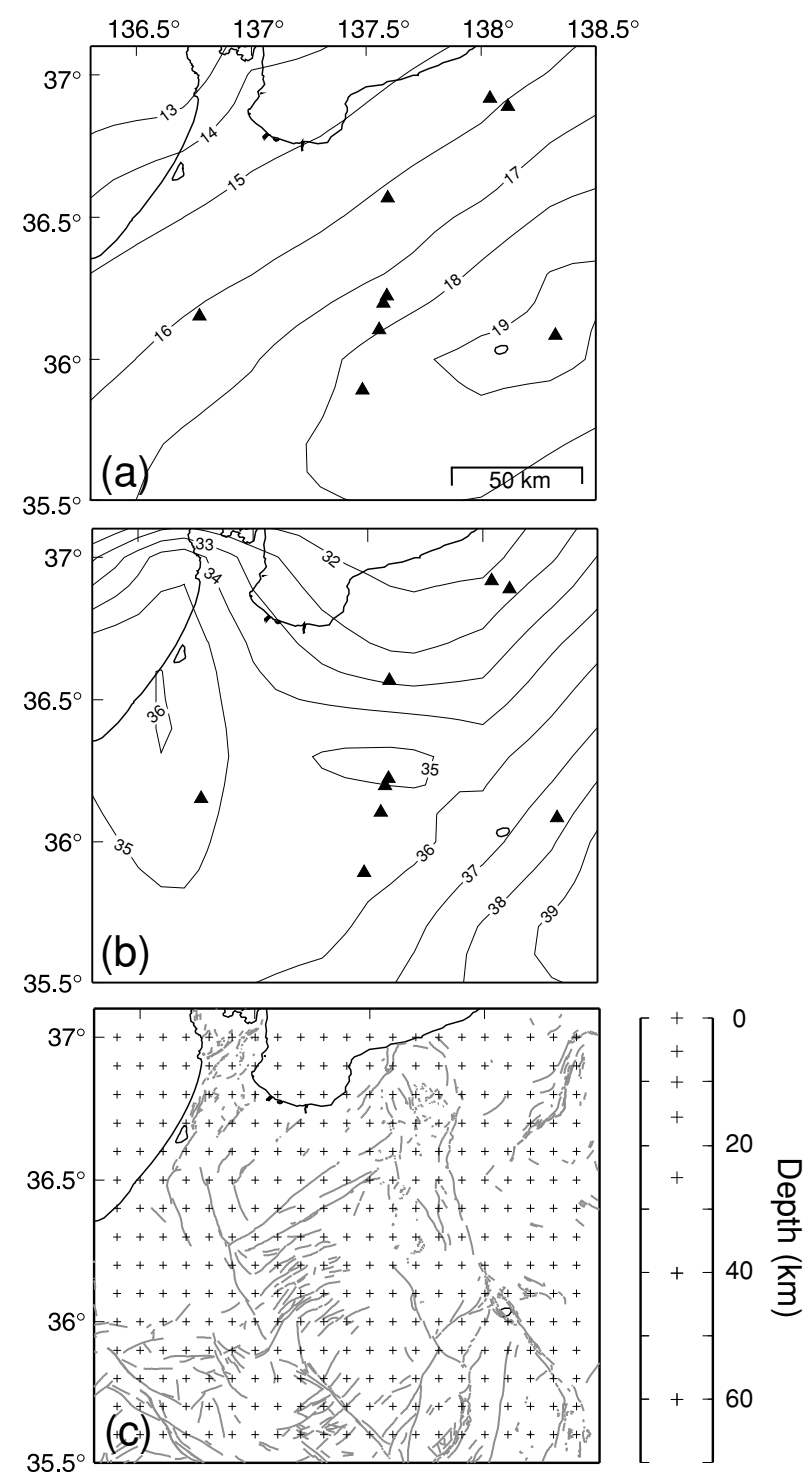

Fig. 4. Depth distribution of (a) the Conrad discontinuity and (b) the Moho discontinuity (Zhao et al., 1992b) used in this study. Triangles denote active volcanoes. (c) Grid configuration adopted for the inversion. Grid spacing in the horizontal direction is $0.1^{\circ}$, and grid nodes are set up at depths of $0,5,10,15,25,40$, and $60 \mathrm{~km}$. Gray lines are active faults.

wave velocity structures. Crustal discontinuities (Conrad and Moho) estimated by Zhao et al. (1992b) and the upper boundary of the Pacific slab (Nakajima et al., 2009) were considered in the inversion (Figs. 4(a) and 4(b)). Because this study focused on small-scale crustal heterogeneity around the Atotsugawa fault, the large-scale crustal framework, including the Conrad and Moho discontinuities and the plate boundary, was assumed a priori based on previous studies. The nonlinear tomographic problem was solved by iterative linear inversions. Perturbations to hypocentral parameters and velocities were determined simultaneously for each iteration. The iterations were terminated when the reduction of the root mean square (RMS) values of the arrival-time residuals converged. Further details of the method are given by Zhao et al. (1992a).

We established the study area as latitudes of $34.4^{\circ}-$ $38.0^{\circ} \mathrm{N}$, longitudes of $135.4^{\circ}-139.6^{\circ} \mathrm{E}$, and depths of 0 

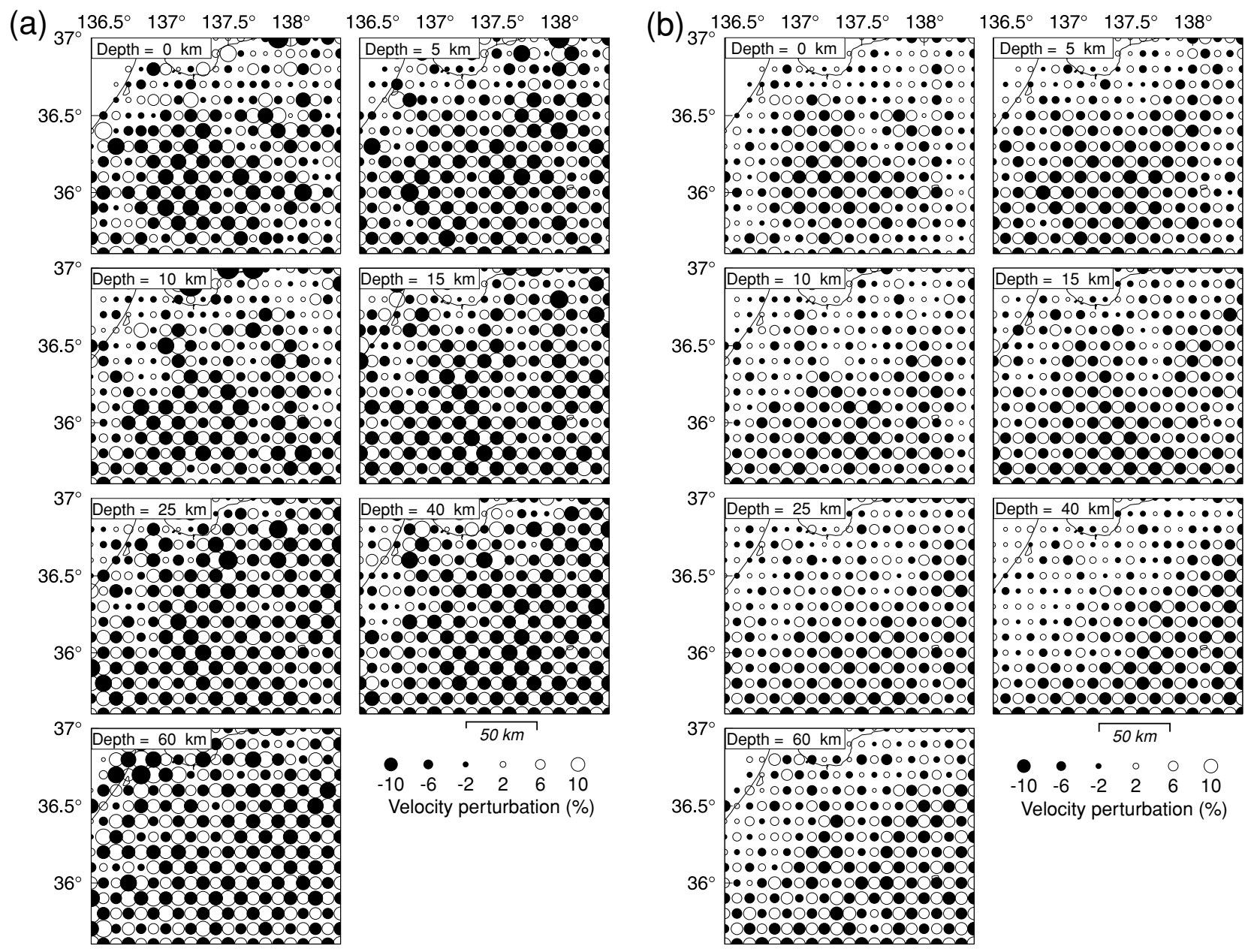

Fig. 5. Results of the checkerboard resolution tests for (a) $P$ and (b) $S$ waves. Solid and open circles denote low and high velocities, respectively.

$400 \mathrm{~km}$. All of the earthquakes and stations were located in this area. However, only the seismic velocities at grid nodes within latitudes of $35.6^{\circ}-37.0^{\circ} \mathrm{N}$, longitudes of $136.4^{\circ}-138.4^{\circ} \mathrm{E}$, and depths of $0-60 \mathrm{~km}$ (hereafter referred to as the inversion area; see Fig. 2) were regarded as unknown parameters. In the inversion area, horizontal grid nodes were set at a spacing of $0.1^{\circ}$ and vertical nodes were set at $0,5,10,15,25,40$, and $60 \mathrm{~km}$ (Fig. 4(c)). When a ray penetrated the inversion area, a weighting factor proportional to the ray length within that area relative to the entire ray length was assigned to each arrival time. If a ray did not intersect the inversion area at all, its weighting factor was zero, and it was not involved in the inversion. We adopted the 3D seismic velocity model of Nakajima and Hasegawa (2007a) as the initial model, and estimated velocity structures in the inversion area. The number of rays intersecting the inversion area was 142,537 for $P$ waves and 89,112 for $S$ waves. Final results were obtained after four iterations. The RMS values of the travel-time residuals, which were 0.14 s for the $P$ waves and 0.27 s for the $S$ waves in the initial model, were reduced to $0.11 \mathrm{~s}$ and $0.25 \mathrm{~s}$, respectively.

\section{Results and Resolution Tests}

\subsection{Checkerboard resolution tests}

We carried out checkerboard resolution tests (CRTs) to evaluate the adequacy of ray coverage and the reliability of the obtained images. In the CRTs, positive and negative velocity perturbations of $10 \%$ were assigned to alternating grid nodes along both the horizontal and vertical directions, and travel times were calculated to generate synthetic data for this model. Synthetic data were constructed using the same source-receiver geometry as the observations, with random noises corresponding to phase-picking errors (a standard deviation of $0.1 \mathrm{~s}$ for $P$ waves and $0.2 \mathrm{~s}$ for $S$ waves). We then inverted the calculated synthetic travel-time data using the initial model without any velocity anomalies.

The results of the CRTs showed good resolution at all depths in the southeastern part of the study area (Fig. 5). The checkerboard patterns in the northwestern part were well recovered for $P$ waves but slightly smeared for $S$ waves, owing to an insufficient number of ray paths propagating in that area. Resolution around the Atotsugawa fault system was relatively good down to a depth of $60 \mathrm{~km}$. We also conducted restoring resolution tests (RRTs) (Zhao et al., 1992a) on the obtained structure. The methods used for ray tracing and inversion were the same as for the CRTs. The results of the RRTs demonstrated the reliability of the obtained images of the region beneath the land area. As discussed below, we performed another synthetic test to confirm the reliability of the obtained images around the Atotsugawa fault system. 
(a)
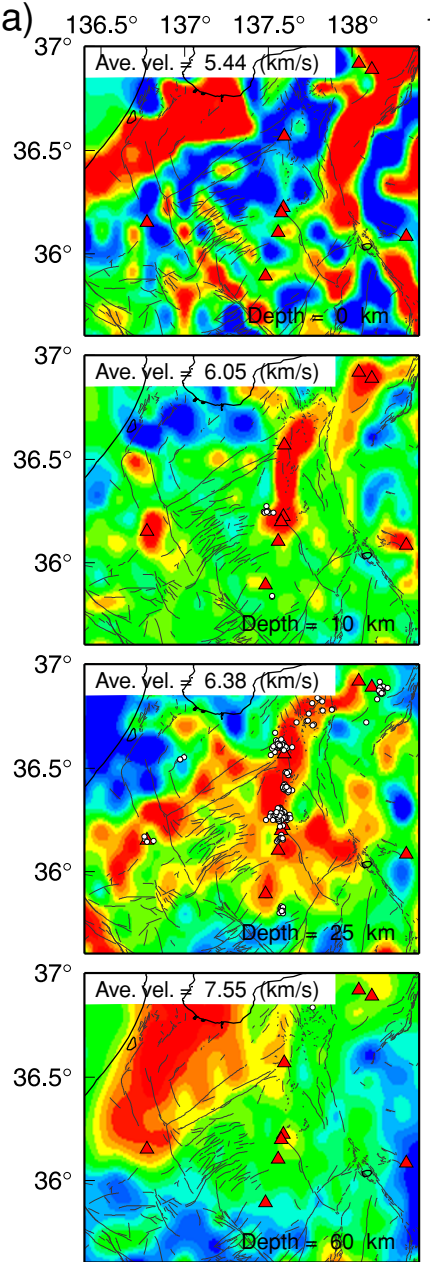

\begin{tabular}{lllllll}
\hline-9 & 1 & 1 & 1 & 1 \\
\hline & -3 & 0 & 3 & 6 & 9
\end{tabular}

Velocity perturbation (\%)
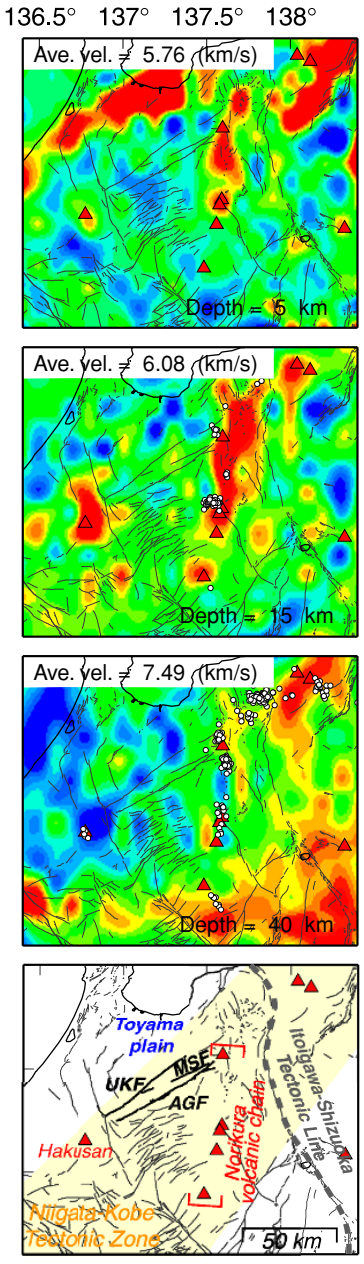

(b)

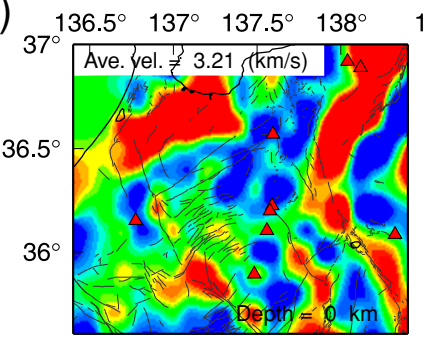

$136.5^{\circ} 137^{\circ} 137.5^{\circ} 138^{\circ}$
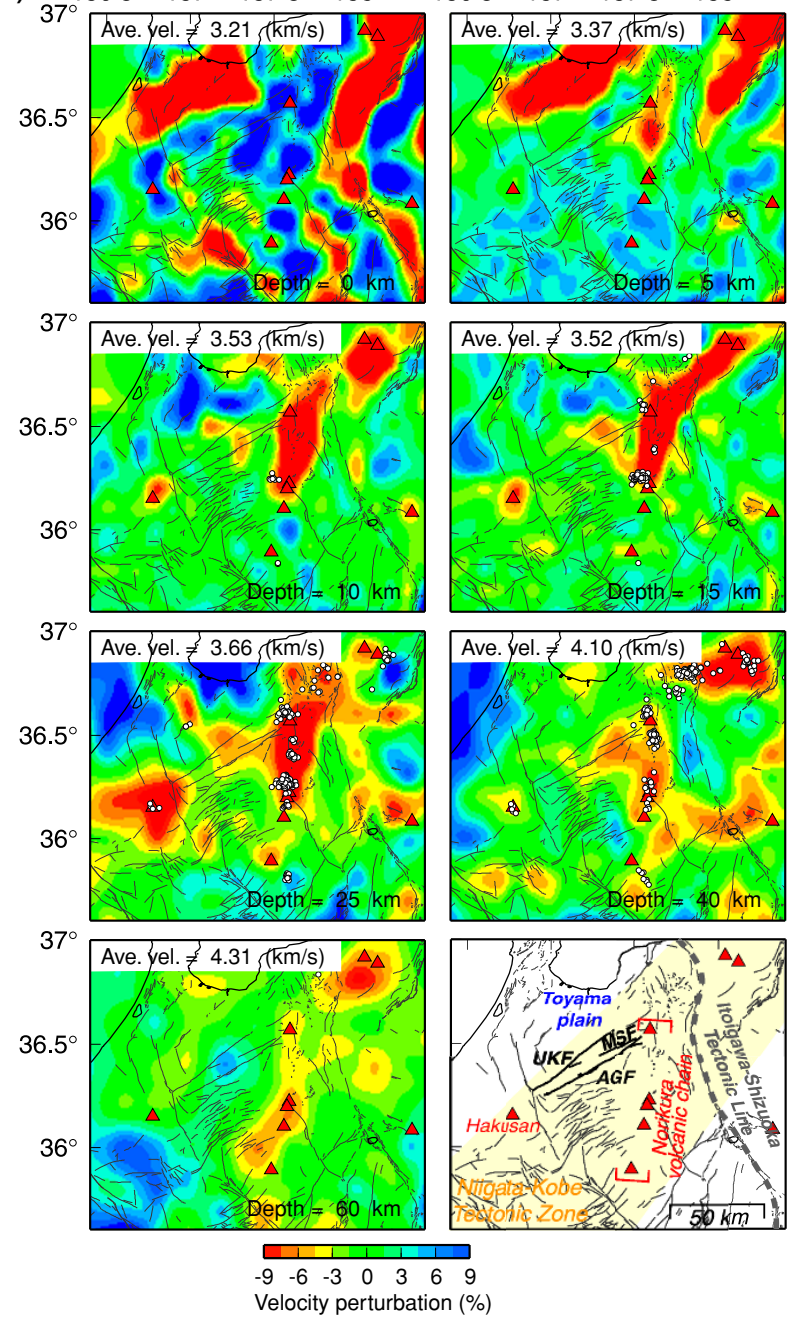

Fig. 6. Distribution of (a) $P$ - and (b) $S$-wave velocity perturbations (in percent). Velocity perturbations are the deviations from the average velocities at each depth calculated for the area shown in this figure. Calculated average velocities are shown in each panel. Red triangles represent active volcanoes, gray lines are active faults, and white circles represent deep low-frequency earthquakes reported by the JMA. The right bottom figure maps regions discussed in the text: AGF, Atotsugawa fault, MSF, Mozumi-Sukenobu fault; UKF, Ushikubi fault.

\subsection{Results}

Figure 6 shows the obtained velocity structures at depths of $0-60 \mathrm{~km}$. Velocity perturbations are the deviations from the average velocity at each depth calculated for the inversion area. Velocity images for $P$ and $S$ waves are very similar at depths of $0-40 \mathrm{~km}$. Two areas with strong lowvelocity anomalies are located at $0 \mathrm{~km}$ depth beneath the Toyama plain and along the Itoigawa-Shizuoka Tectonic Line. The Toyama plain also has a low-velocity anomaly at a depth of $5 \mathrm{~km}$. Low-velocity anomalies are imaged around Hakusan volcano and along the Norikura volcanic chain at depths of 5-15 km. The Atotsugawa fault system shows a moderate seismic velocity at a depth of $5 \mathrm{~km}$, whereas an isolated low-velocity anomaly exists in the central section at depths of $10-15 \mathrm{~km}$, in particular for $S$ waves. In the lower crust (25 km depth), a distinct low-velocity anomaly is imaged along the Atotsugawa fault system as well as beneath volcanic areas. $S$-wave low-velocity anomalies are distributed around volcanoes at a depth of $40 \mathrm{~km}$.

Our results indicate structural heterogeneity along and across the Atotsugawa fault (Figs. 7 and 8). Extreme low- velocity anomalies are distributed throughout the crust on the eastern and western ends of the Atotsugawa fault, where volcanoes exist at the surface. Values of $V_{p} / V_{s}$ ratios in these areas are generally larger $(>\sim 1.8)$ in the middle to lower crust and low to moderate $(1.7-1.75)$ in the upper crust (Fig. 7). Deep, low-frequency earthquakes occur mainly in the areas with low-velocity anomalies. The middle to lower crust beneath the Atotsugawa fault shows a low-velocity anomaly with low to moderate $V_{p} / V_{s}$ ratios (1.7-1.75). The low-velocity zone beneath the Atotsugawa fault system can be clearly seen in two of three across-fault vertical cross sections, particularly for $S$ waves (Fig. 8). Another important point is the existence of a horizontally isolated low-velocity anomaly in the central section of the Atotsugawa fault at a depth of $10 \mathrm{~km}$ (white arrow in Fig. 7(b)). This low-velocity zone appears to correlate spatially with the bowl-like seismicity pattern, as discussed in Section 4.4. Most of the earthquakes occurring along the fault are distributed in areas with $V_{p}>6.0 \mathrm{~km} / \mathrm{s}$ and $V_{s}>3.5 \mathrm{~km} / \mathrm{s}$.

To evaluate the relationship between seismic activity and 

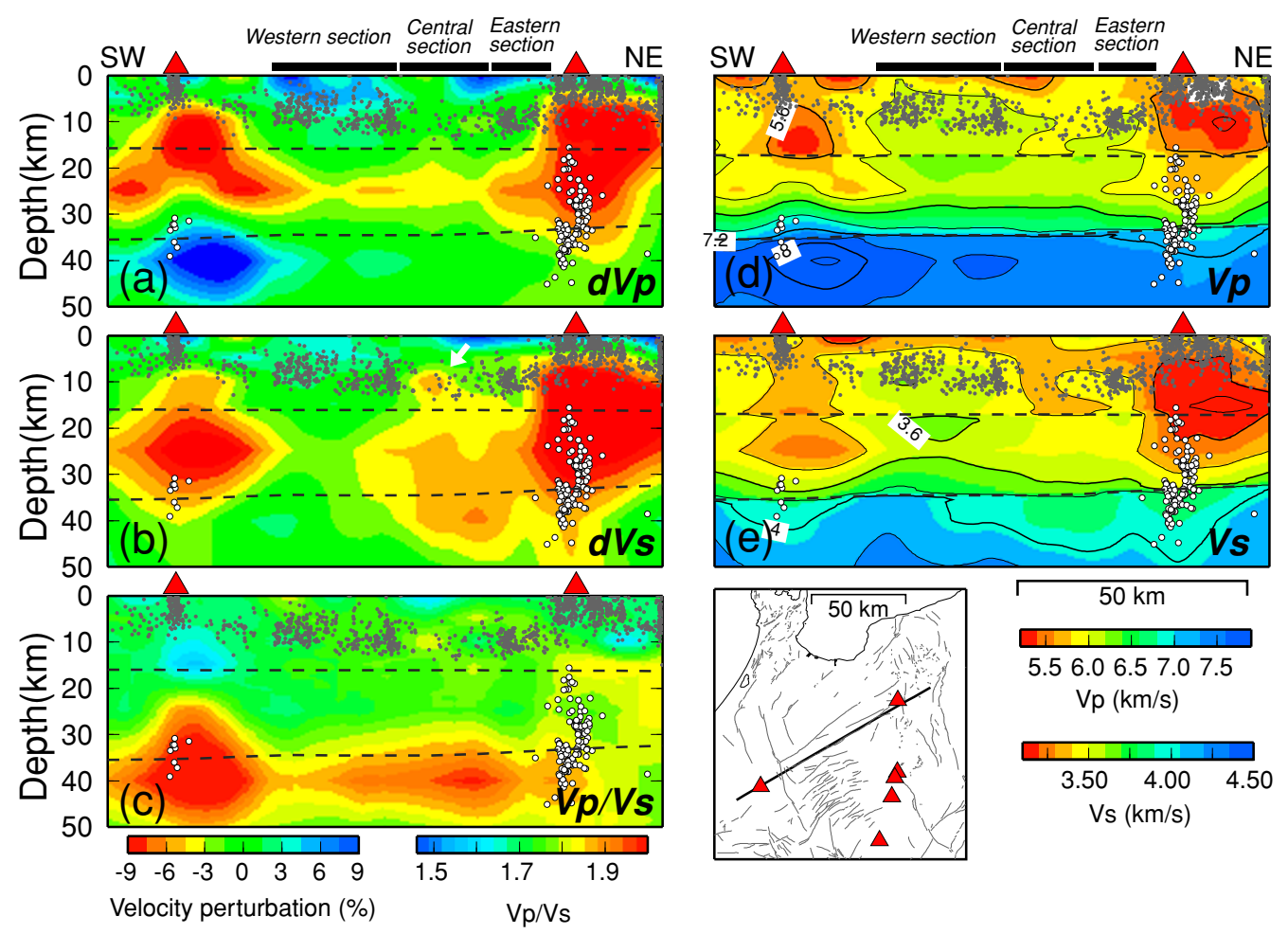

Fig. 7. Along-fault vertical cross sections of (a) $P$ - and (b) $S$-wave velocity perturbations, (c) $V_{p} / V_{s}$ values, and (d) $P$ - and (e) $S$-wave absolute velocities along the line shown in the inset map. Gray and white circles denote earthquakes and low-frequency earthquakes relocated with the final $3 \mathrm{D}$ velocity models, respectively. Earthquakes within $10 \mathrm{~km}$ of the line are plotted. The shallower and deeper black dashed lines in each panel show the Conrad and Moho discontinuities, respectively, adopted in the inversion (Zhao et al., 1992b). The white arrow in (b) indicates the low-velocity anomaly in the upper crust discussed in the text.

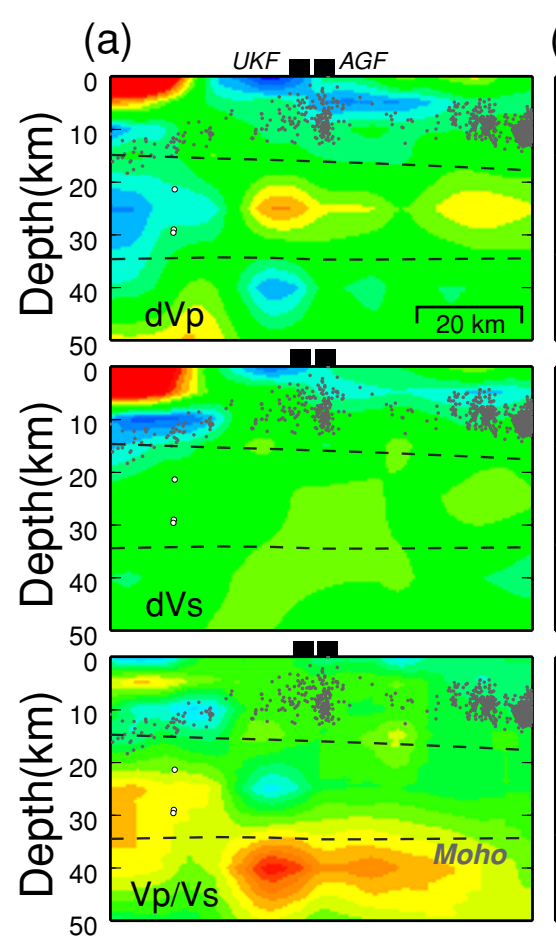

(b)

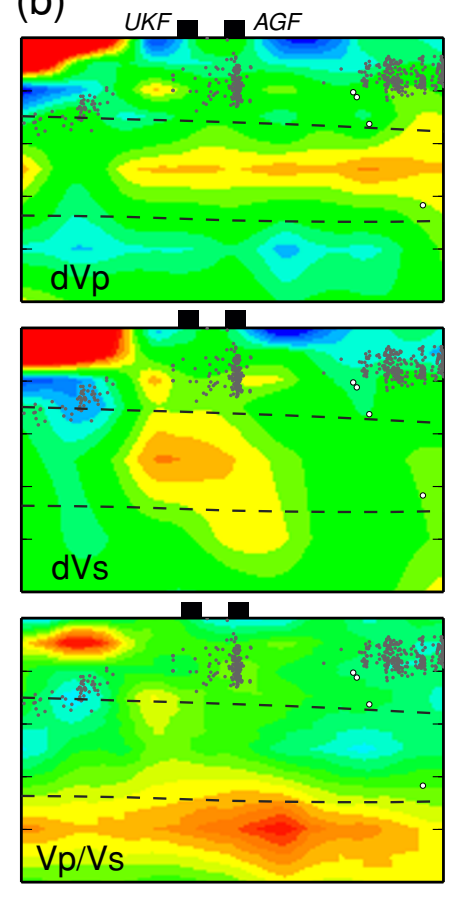

(c)

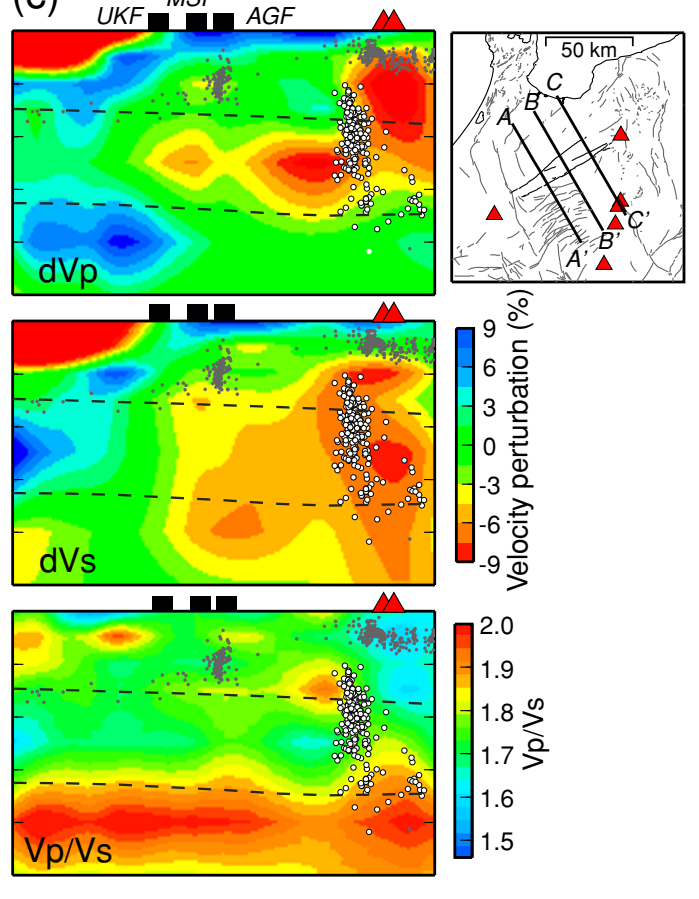

Fig. 8. Across-fault vertical cross sections of $P$ - and $S$-wave velocity perturbations and $V_{p} / V_{s}$ values along (a) line A-A', (b) line B-B', and (c) line $\mathrm{C}-\mathrm{C}^{\prime}$ in the inset map. Black squares mark surface traces of the Atotsugawa (AGF), Mozumi-Sukenobu (MSF), and Ushikubi (UKF) faults. The other symbols are the same as in Fig. 7. 
structural heterogeneity, we selected 53,521 ordinary and 587 low-frequency earthquakes with phase picks at 10 or more stations from the JMA-unified catalogue in 20012007 , and relocated them with the 3D velocity model obtained in this study. The relocated hypocenters are used for discussion below. Vertical errors for the relocated hypocenters were generally less than $1-2 \mathrm{~km}$.

\section{Discussion}

4.1 Velocity heterogeneity in the lower crust: Evidence for fluid concentration beneath the Atotsugawa fault

Figure 9 compares the $P$ - and $S$-wave velocity structures at a depth of $25 \mathrm{~km}$ obtained in this study with those of Nakajima and Hasegawa (2007a). Nakajima and Hasegawa (2007a) applied a travel-time tomography method to arrivaltime data from the nationwide seismograph network using grid nodes with a horizontal spacing of $0.2^{\circ}$. They identified a low-velocity anomaly $\left(V_{p}<\sim 6.4 \mathrm{~km} / \mathrm{s}\right.$ and $V_{s}<\sim$ $3.6 \mathrm{~km} / \mathrm{s}$ ) with a width of $\sim 100 \mathrm{~km}$ in the lower crust along the NKTZ, which they interpreted to be caused by aqueous fluids supplied from the uppermost mantle.

Our study updates seismic velocities in the lower crust beneath the NKTZ, ranging from $\sim 5.6$ to $\sim 7.0 \mathrm{~km} / \mathrm{s}$ (average $6.31 \mathrm{~km} / \mathrm{s}$ ) for $P$ waves and from $\sim 3.2$ to $\sim 4.0 \mathrm{~km} / \mathrm{s}$ (average $3.62 \mathrm{~km} / \mathrm{s}$ ) for $S$ waves (Figs. 9 and 10). We also reveal a strong lower-velocity anomaly beneath the Atotsugawa fault system, which is distributed subparallel to the strike of the fault system and is about $20-30 \mathrm{~km}$ wide (Figs. 9(a) and (b)). Seismic velocities in this zone range from $\sim 5.5$ to $\sim 6.3 \mathrm{~km} / \mathrm{s}$ (average $6.00 \mathrm{~km} / \mathrm{s}$ ) for $P$ waves and from $\sim 3.4$ to $\sim 3.6 \mathrm{~km} / \mathrm{s}$ (average $3.52 \mathrm{~km} / \mathrm{s}$ ) for $S$ waves (Fig. 10). These observations suggest a hierarchical structure of low-velocity anomalies around the Atotsugawa fault system.

In a sensitivity test to assess the reliability of our results, we assigned velocity anomalies of $-12 \%$ and $-5 \%$ to grid nodes beneath the Atotsugawa fault system and its surroundings, respectively (Fig. 11(c)). Calculations of synthetic travel times and the inversion scheme were the same as for the CRTs. The test showed that the hierarchical structure can be satisfactorily resolved by the data set used in this study (Figs. 11(a) and (b)), suggesting that the obtained structure for the lower crust is reliable.

$P$ - and $S$-wave velocities for lower crustal rocks have been determined in the laboratory (e.g., Kern et al., 1999; Kono et al., 2006; Nishimoto et al., 2008). Nishimoto et al. (2008) simultaneously measured $P$ - and $S$-wave velocities of five mafic xenoliths from northeastern Japan under subsolidus conditions up to $1.0 \mathrm{GPa}$ and $800^{\circ} \mathrm{C}$, and estimated $P$ - and $S$-wave velocities as functions of temperature and pressure under dry conditions. Seismic velocities for these five rocks at $0.8 \mathrm{GPa}$ and $740^{\circ} \mathrm{C}$ are shown by orange and gray symbols in Fig. 10. The temperature of $740^{\circ} \mathrm{C}$ was estimated from the heat flow of $80 \mathrm{~mW} / \mathrm{m}^{2}$ and heat transfer coefficient of $2.7 \mathrm{~W} / \mathrm{K} \mathrm{m}$, following Kagami and Watanabe (2009). We here compare these laboratory-derived seismic velocities with those we observed in the lower crust beneath the Atotsugawa fault (red crosses in Fig. 10) and beneath the NKTZ (blue crosses in Fig. 10), and discuss quantitatively
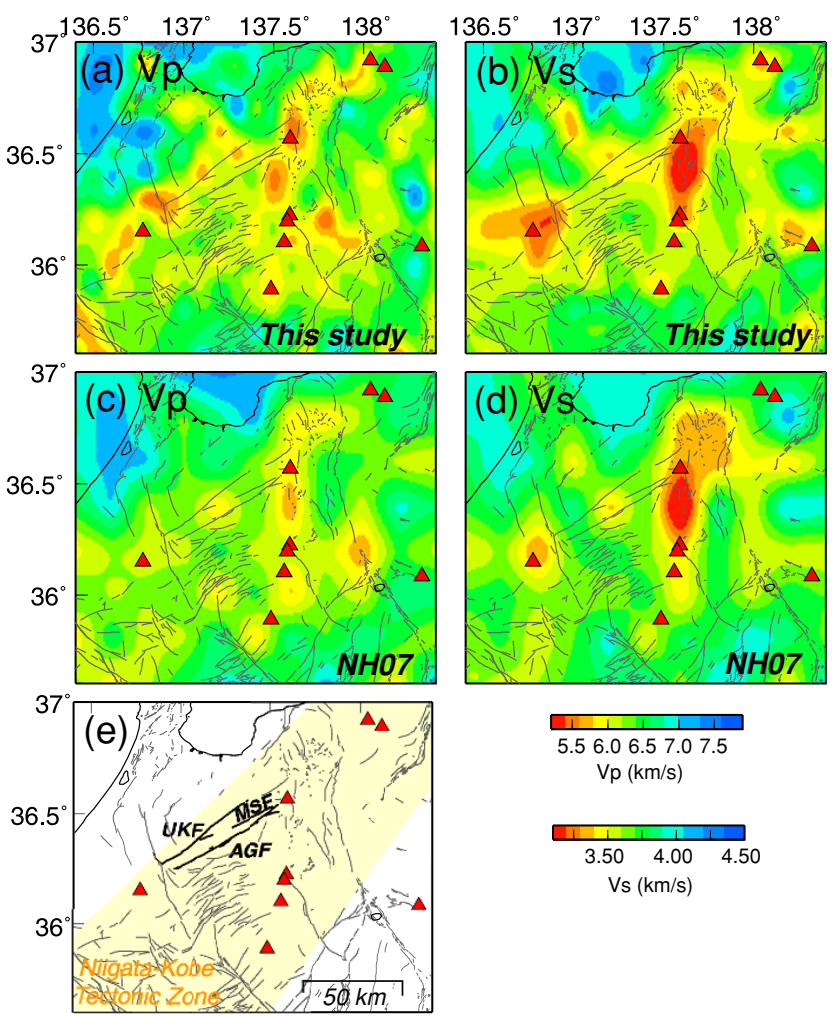

$\mathrm{Vp}(\mathrm{km} / \mathrm{s})$

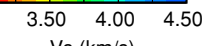

Vs $(\mathrm{km} / \mathrm{s})$

Fig. 9. Comparison of (a) $P$ - and (b) $S$-wave velocity distributions at a depth of $25 \mathrm{~km}$ obtained in this study with (c) $P$ - and (d) $S$-wave velocity distributions obtained by Nakajima and Hasegawa (2007a) (NH07).

(e) Locations of the Atotsugawa (AGF), Mozumi-Sukenobu (MSF), and Ushikubi (UKF) faults and the NKTZ.

the cause of the low-velocity anomalies. To exclude lowvelocity anomalies related to magmatic activity, we considered seismic velocities only at grid nodes more than $20 \mathrm{~km}$ away from active volcanoes.

Temperature derivatives of the rocks measured by Nishimoto et al. (2008) are less than $0.09 \mathrm{~km} \mathrm{~s}^{-1} / 100^{\circ} \mathrm{C}$ for $P$ waves and $0.05 \mathrm{~km} \mathrm{~s}^{-1} / 100^{\circ} \mathrm{C}$ for $S$ waves, which requires unrealistically high temperatures of up to 1300 $1500^{\circ} \mathrm{C}$ to explain the observed seismic velocities if only thermal variation is considered. However, solidus temperatures for lower-crustal rocks are considered to be $\sim 800^{\circ} \mathrm{C}$ (e.g., Nishimoto et al., 2008), and the resultant generation of partial melts yields high $V_{p} / V_{s}$ values (e.g., Takei, 2002) rather than the low $V_{p} / V_{s}$ values observed in this study. Moreover, as discussed below, high-temperature conditions would not be expected in the central section based on the bowl-shaped distribution of seismicity along the Atotsugawa fault. Therefore, we propose that the presence of aqueous fluids $\left(\mathrm{H}_{2} \mathrm{O}\right)$ has a predominant effect on the low-velocity anomaly in the lower crust, and estimate aspect ratios and volume fractions of $\mathrm{H}_{2} \mathrm{O}$ from the observed seismic velocities.

Takei (2002) showed that the existence of $\mathrm{H}_{2} \mathrm{O}$-filled pores has different effects on seismic velocity, particularly on Poisson's ratio, depending on the shape of the pores. $\mathrm{H}_{2} \mathrm{O}$-filled pores with an aspect ratio smaller than $\sim 0.1$ increase Poisson's ratio with decreasing seismic velocity, which has an effect identical to that of melt-filled pores. In contrast, $\mathrm{H}_{2} \mathrm{O}$-filled pores with an aspect ratio larger than 


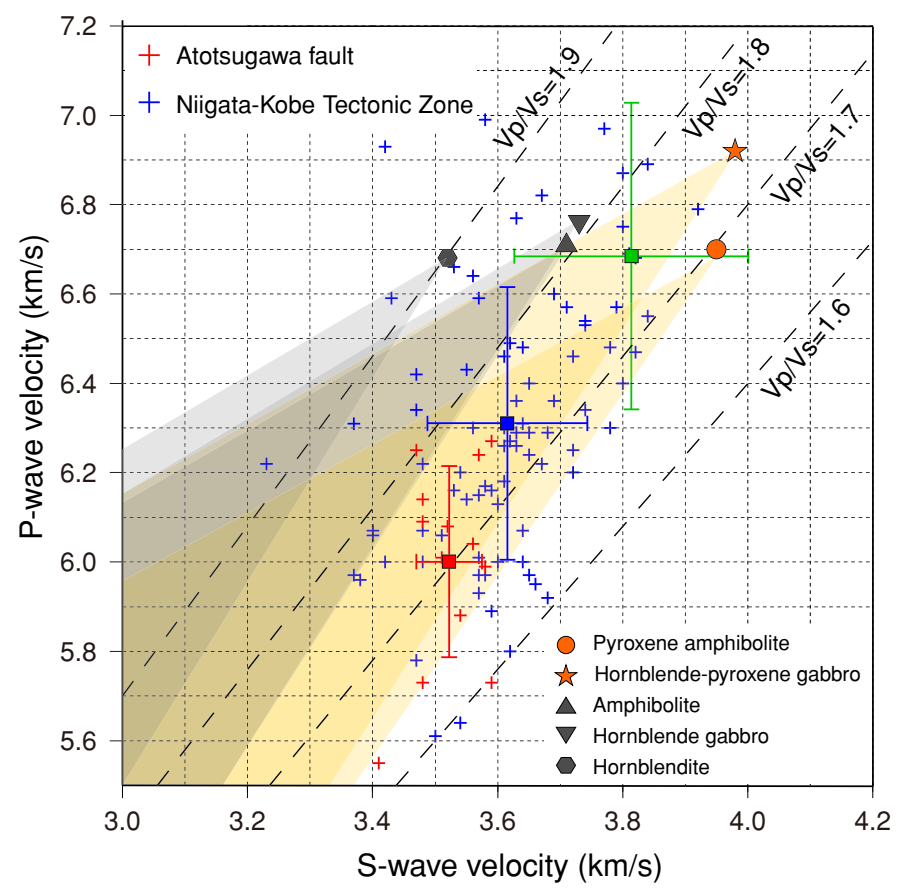

Fig. 10. Comparison of observed $P$ - and $S$-wave velocities with experimental velocities from Nishimoto et al. (2008). Red and blue crosses denote the observed $P$ - and $S$-wave velocities beneath the Atotsugawa fault system (velocities at grid nodes within $10 \mathrm{~km}$ of the surface trace of the Atotsugawa fault) and the NKTZ (velocities at grid nodes located below the NKTZ), respectively. An average $P$ - and $S$-wave velocity for each region is shown by a colored square with error bars of one standard deviation. For comparison, an average $P$ - and $S$-wave velocity outside the NKTZ estimated by Nakajima and Hasegawa (2007a) is indicated by a green square. Seismic velocities at grid nodes less than $20 \mathrm{~km}$ from active volcanoes were not used for calculation. Orange and gray symbols show $P$ - and $S$-wave velocities of five rocks measured by Nishimoto $e t$ al. (2008) at a temperature of $740^{\circ} \mathrm{C}$ and a pressure of $0.8 \mathrm{GPa}$. Shaded areas denote the range of seismic velocities explained by the existence of aqueous fluids based on the theory of Takei (2002).

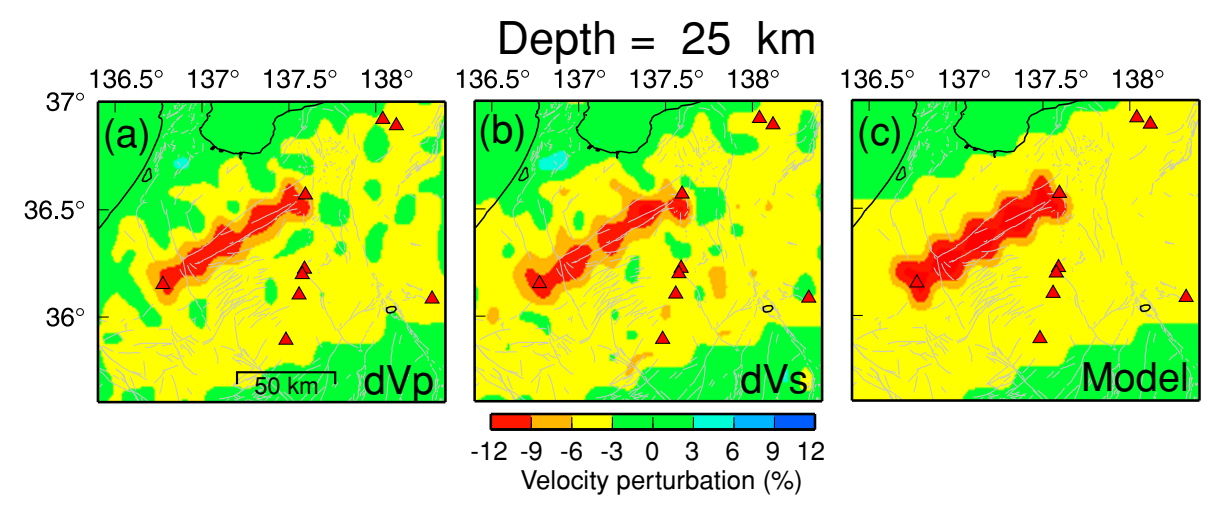

Fig. 11. Sensitivity test for a hierarchical structure of low-velocity zone around the Atotsugawa fault system. Results of the sensitivity test for (a) $P$ and (b) $S$ waves at a depth of $25 \mathrm{~km}$. (c) The input model for the test.

Table 1. Observed velocity reduction and aspect ratio and fluid fraction of $\mathrm{H}_{2} \mathrm{O}$-filled pores in the lower crust.

\begin{tabular}{|l|c|c|c|c|}
\hline & \multicolumn{2}{|c|}{ Atotsugawa fault system } & \multicolumn{2}{c|}{ Niigata-Kobe Tectonic Zone } \\
\cline { 2 - 5 } & Pyroxene amphibolite & Hornblende-pyroxene gabbro & Pyroxene amphibolite & Hornblende-pyroxene gabbro \\
\hline $\ln V_{p}$ & -0.10 & -0.13 & -0.058 & -0.088 \\
$d \ln V_{s}$ & -0.11 & -0.12 & -0.085 & -0.092 \\
$d \ln V_{s} / d \ln V_{p}$ & 1.10 & 0.92 & 1.44 & 1.05 \\
Aspect ratio & $0.04-0.05$ & $\sim 0.2$ & $0.01-0.02$ & $0.05-0.06$ \\
Volume fraction & $2-3 \%$ & $\sim 10 \%$ & $\sim 0.8 \%$ & $3-4 \%$ \\
\hline
\end{tabular}

$\sim 0.1$ lower Poisson's ratio with decreasing seismic velocity. Takei (2002) also demonstrated that aspect ratios of $\mathrm{H}_{2} \mathrm{O}$-filled pores can be estimated from a ratio of velocity reduction between $P$ and $S$ waves, and that volume frac- tions of $\mathrm{H}_{2} \mathrm{O}$ can be calculated in turn from the estimated aspect ratio and the reduction rate of $S$-wave velocity. The shaded areas in Fig. 10 show acceptable ranges of $P$ - and $S$-wave velocities, based on the theory of Takei (2002), if 


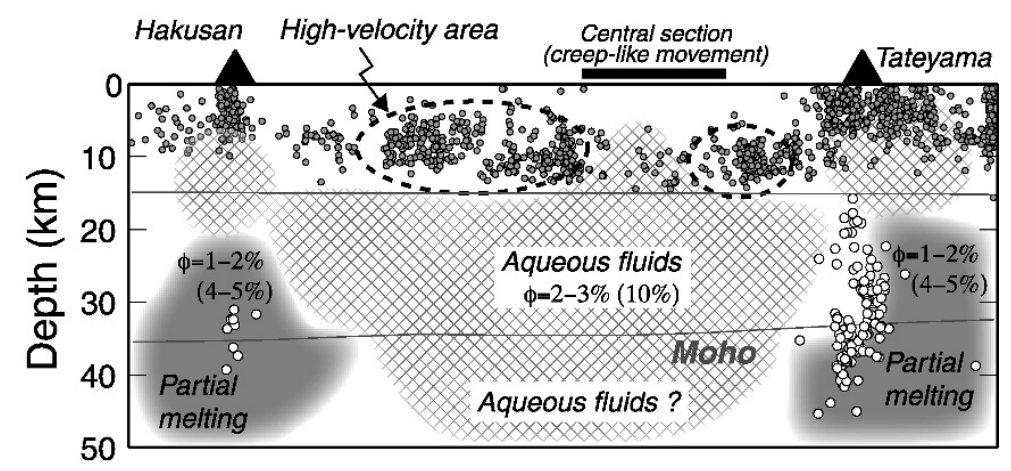

Fig. 12. Schematic interpretation of velocity heterogeneity along the Atotsugawa fault. Gray and white circles denote small earthquakes and low-frequency earthquakes, respectively. The estimated uid fraction $(\phi)$ are shown for pyroxene amphibolite and for hornblende-pyroxene gabbro (in parentheses). Note that volume fractions of aqueous uids for the horizontally isolated low-velocity zone in the upper crust beneath the central section are estimated to be $0.2-0.3 \%$.

each host rock contains some amount of $\mathrm{H}_{2} \mathrm{O}$ - lled pores.

Figure 10 shows that only pyroxene amphibolite or hornblende-pyroxene gabbro with $\mathrm{H}_{2} \mathrm{O}$ - lled pores can explain the majority of $P$ - and $S$-wave velocities observed beneath the Atotsugawa fault system and the NKTZ. Therefore, we assume pyroxene amphibolite and hornblendepyroxene gabbro as the host rocks in the lower crust, and estimate aspect ratios and volume fractions of $\mathrm{H}_{2} \mathrm{O}$ - lled pores from $P$ - and $S$-wave velocity reduction rates $\left(d \ln V_{p}\right.$ and $d \ln V_{s}$ ) relative to $P$ - and $S$-wave velocities of each rock under dry conditions, using the theory of Takei (2002). The observed values of $d \ln V_{p}$ and $d \ln V_{s}$, and the estimated aspect ratios and volume fractions of $\mathrm{H}_{2} \mathrm{O}$ - lled pores, are summarized in Table 1. The lower crust beneath the Atotsugawa fault contains $2-3 \% \mathrm{H}_{2} \mathrm{O}$ for pyroxene amphibolite and $\sim 10 \% \mathrm{H}_{2} \mathrm{O}$ for hornblende-pyroxene gabbro (Fig. 12). These uid fractions are 3-4 times larger than those in the lower crust beneath the NKTZ (Table 1), suggesting the development of a hierarchical structure in terms of uid content. Notably, an average seismic velocity outside the NKTZ estimated by Nakajima and Hasegawa (2007a) (green square in Fig. 10) is comparable to seismic velocity of dry rocks measured by Nishimoto et al. (2008), which has important implications for the absence of a large volume of $\mathrm{H}_{2} \mathrm{O}$ outside the NKTZ.

Mizuno et al. (2005) showed that the angle between the strike of the Atotsugawa fault and the direction of the maximum horizontal stress inferred from shear-wave splitting analysis ranges from $55^{\circ}$ to $80^{\circ}$ at stations $2-8 \mathrm{~km}$ away from the fault and approaches $\sim 45^{\circ}$ at stations within $1 \mathrm{~km}$ of the fault. From their nite-element modeling of the stress eld around the fault, they interpreted this feature as caused by local stress accumulation due to localized ow or slip along the deep extension of the fault. Iio et al. (2002, 2004) proposed a model in which a weak zone with low viscosity in the lower crust beneath the NKTZ is responsible for concentrated deformation at the surface. The presence of abundant uids beneath the Atotsugawa fault system could reduce the strength of the lower crust, which could help localize deformation above it under a regional stress regime. Our results suggest that a water-weakened lower crust plays an important role in stress accumulation along the Atotsugawa fault system.

\subsection{Low-velocity zones beneath volcanoes on the both ends of the Atotsugawa fault}

We observe prominent low-velocity anomalies around the volcanoes at the ends of the Atotsugawa fault. Average velocities immediately below Tateyama and Hakusan volcanoes are $5.22 \mathrm{~km} / \mathrm{s}$ for $P$ waves and $3.02 \mathrm{~km} / \mathrm{s}$ for $S$ waves at a depth of $10 \mathrm{~km}$, and $5.93 \mathrm{~km} / \mathrm{s}$ for $P$ waves and $3.17 \mathrm{~km} / \mathrm{s}$ for $S$ waves at a depth of $25 \mathrm{~km}$, yielding moderate $V_{p} / V_{s}$ values of $\sim 1.73$ in the upper crust and high values of $\sim 1.87$ in the lower crust. Similar features have also been observed in volcanic areas of northeastern Japan (Nakajima et al., 2001).

Geochemical analyses of rock samples have suggested lower crustal melting beneath Hakusan (Ujike and Mashimo, 2009) and the existence of a basaltic magma chamber in the lower crust beneath Ontake volcano, located south of Tateyama (Kimura and Yoshida, 1999). Therefore, under the assumption that partial melting occurs in the lower crust, we evaluate aspect ratios and volume fractions of melts beneath the two volcanoes. Values of $d \ln V_{p}$ and $d \ln V_{s}$ are calculated to be -0.13 for $P$ waves and -0.20 for $S$ waves for hornblende-pyroxene gabbro, and -0.10 for $P$ waves and -0.19 for $S$ waves for pyroxene amphibolite. The corresponding aspect ratios and fractions of melt- lled pores are estimated to be $0.03-0.04$ and 4-5\%, respectively, for hornblende-pyroxene gabbro and $\sim 0.01$ and $1-2 \%$, respectively, for pyroxene amphibolite (Fig. 12).

The observed moderate values of $V_{p} / V_{s}$ in the upper crust suggest the absence of volumes of partial melting comparable to the spatial resolution $(\sim 10 \mathrm{~km})$ of seismic tomography, because the existence of partial melts causes high $V_{p} / V_{s}$ values regardless of pore shapes (Takei, 2002). However, Matsubara et al. (2000) detected a small $(\sim 5 \mathrm{~km})$ conduit-like zone of low $P$-wave velocity (4.1$5.5 \mathrm{~km} / \mathrm{s})$ and high $V_{p} / V_{s}(1.8-2.7)$ in the upper crust immediately below Tateyama, and interpreted it caused by partially molten material with a uid fraction of 5-15\%. Thus, low-velocity and moderate $V_{p} / V_{s}$ values observed in this study prefer to a large volume of aqueous uids possibly with smaller-scale partial melting.

\subsection{Deep origin of fluids in the lower crust}

Figure 13 shows a large-scale vertical cross section of $S$-wave velocity perturbation obtained by Nakajima and 


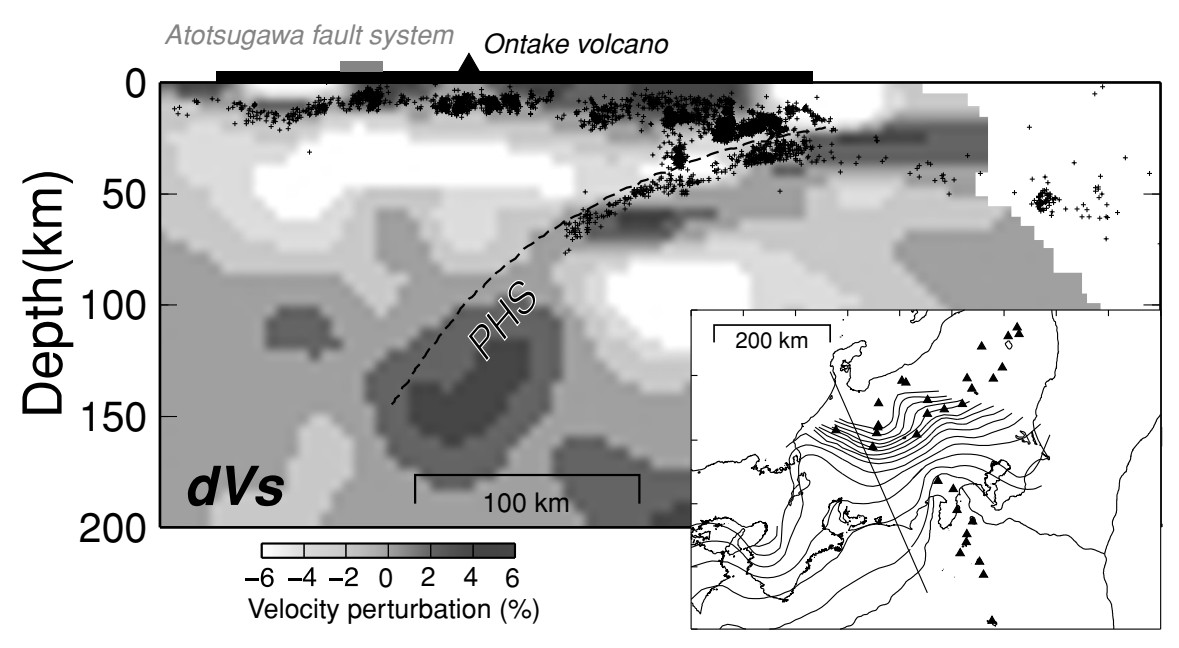

Fig. 13. Vertical cross section of $S$-wave velocity perturbations along the line in the insert map (after Nakajima and Hasegawa, 2007b). Crosses denote earthquakes. The dashed line labeled PHS represents the upper surface of the Philippine Sea slab (Hirose et al., 2007, 2008; Nakajima et al., 2009). The black bar, black triangle, and gray bar on the top denote the land area, active Ontake volcano, and the surface trace of the Atotsugawa fault system, respectively.

Hasegawa (2007b) that crosses the Atotsugawa fault. The subduction of the Philippine Sea slab is imaged down to a depth of $\sim 140 \mathrm{~km}$, and a low-velocity zone is distributed in the mantle wedge at depths shallower than $\sim 80 \mathrm{~km}$. Another vertical cross section crossing Hakusan volcano with a NNE-SSW strike also shows the existence of a lowvelocity zone extending to a depth of $\sim 150 \mathrm{~km}$ (see figure 11(a) in Nakajima and Hasegawa, 2007b). Nakajima and Hasegawa (2007b) interpreted the low-velocity zone in the mantle wedge as being associated with upwelling flow induced by the subduction of the Philippine Sea slab.

Iidaka et al. (2009) investigated shear-wave splitting in central Japan and demonstrated the existence of mantle anisotropy in the N-S direction beneath the Atotsugawa fault. They attributed their observations to a preferred orientation of olivine caused by mantle return flow induced by the subduction of the Philippine Sea slab or to the alignment of melt-filled cracks in the return flow, supporting the existence of upwelling flow in the mantle. Nakamura et al. (2008) pointed out that a relatively large amount of fluids from the Philippine Sea plate contributes to magmatism at Hakusan. Ujike and Mashimo (2009) also suggested that adakitic magmas erupting from Hakusan are affected by fluids from the oceanic crust of the subducting Philippine Sea plate. These results suggest that aqueous fluids originating from the subducting Philippine Sea slab migrate through the upwelling flow and are consequently supplied to the lower crust around the Atotsugawa fault as well as the NKTZ.

4.4 Velocity heterogeneity in the upper crust along the Atotsugawa fault: Implications for fault creep

A notable point is the presence of a low-velocity anomaly beneath the central section of the Atotsugawa fault at a depth of $10 \mathrm{~km}$, with higher-velocity regions on both sides (Fig. 7(b)). This region has $P$-wave velocities of 5.8$6.0 \mathrm{~km} / \mathrm{s}$ and $S$-wave velocities of $3.3-3.4 \mathrm{~km} / \mathrm{s}$. Kato et al. (2007) used arrival-time data from a dense temporary seismic network with a station separation of $\sim 1 \mathrm{~km}$, and revealed high-velocity bodies in the western and eastern sections and a low-velocity body in the central section at depths of 2-7 km. Our results are consistent with the results of Kato et al. (2007) and suggest that such features extend at least to a depth of $\sim 10 \mathrm{~km}$.

The structural heterogeneity revealed in this study appears to correlate spatially with seismic activity along the Atotsugawa fault. Seismic activity is very high in the highvelocity anomalies in the western and eastern sections with $V_{p}>6.0 \mathrm{~km} / \mathrm{s}$ and $V_{s}>3.5 \mathrm{~km} / \mathrm{s}$, whereas in the central section seismic velocities are relatively low and creeplike movement has been observed at the surface (Geographical Survey Institute, 1997). We consider high-velocity anomalies to be associated with more brittle and competent parts of the upper crust that can sustain seismogenic stress, possibly acting as an asperity on the fault plane. Kato et al. $(2006,2007)$ argued that the high-velocity anomaly in the western section, where a high-resistivity body (Goto et al., 2005) and a low-scattering feature (Nishigami, 2007) have been observed, acted as a high-slip asperity in the 1858 Hietsu earthquake (Takeuchi et al., 2003). The eastern section shows a slight high-velocity anomaly compared to the central section, but its lateral extent is limited to $10-15 \mathrm{~km}$. This implies that an earthquake potentially occurring in the eastern section would be much smaller than in the western section, unless a rupture propagates across the low-velocity central section. Frictional and physical properties in the isolated low-velocity zone of the central section are therefore very important in terms of seismic hazard along the fault.

Kato et al. (2007) suggested that the low-velocity zone imaged in the upper crust in the central section reflects velocity reduction of basement rocks by crustal fluids. We observe velocity reductions from average velocities of 1$4 \%$ for $P$ waves and 3-6\% for $S$ waves in the low-velocity anomaly in the central section, which can be explained by the existence of $\mathrm{H}_{2} \mathrm{O}$-filled pores with aspect ratio of $\sim 0.01$ and a volume fraction of $0.2-0.3 \%$ (Takei, 2002). The lowvelocity anomaly at a depth of $10 \mathrm{~km}$ appears to be connected with the low-velocity anomaly below the seismogenic layer (Fig. 7), suggesting that fluids are supplied continuously from the lower crust and that effective pore pres- 
sure in that region becomes relatively high. Because the seismogenic layer is thickest in the central section, we infer that temperatures of aqueous uids supplied to the central section are not so high (Fig. 12).

High pore- uid pressure in the low-velocity zone of the central section may enhance the stability of frictional slip (Scholz, 1998), resulting in aseismic or episodic slip along the fault. Consequently, creeplike movement and low seismicity are associated with high pore- uid pressures in the central section, as discussed by Kato et al. (2007). Jin et al. (2000) investigated the source parameters of 102 small earthquakes along the Atotsugawa fault and found that earthquakes at depths of $11-13 \mathrm{~km}$ in the creeping section have a lower stress drop $(<0.1 \mathrm{MPa})$ than those in other portions of the Atotsugawa fault. They suggested that the friction along the fault may be relatively low and these earthquakes may have a character intermediate between regular earthquakes and creep events. These results are consistent with our observations that the low-velocity anomaly, probably caused by the presence of aqueous uids, exist at a depth of $\sim 10 \mathrm{~km}$ in the central section.

In contrast, Mizoguchi et al. (2007) carried out friction experiments using fault gouge samples collected from the Atotsugawa fault and found an increase in the frictional coef cient from 0.50 to 0.58 with depth from 1 to $9 \mathrm{~km}$. They proposed a model in which depth-dependent frictional strength can generate creeplike movements at shallower depths, because stress on the fault can result in low frictional strength at shallow depths earlier than at greater depths. However, a concentration of crustal uids at a depth of $10 \mathrm{~km}$ discussed in this study could lower the effective frictional coef cient there. We need to determine structural heterogeneity along the Atotsugawa fault in much greater detail to develop a better model for explaining creeplike movement in the central section.

\section{Conclusions}

We estimated detailed seismic velocity structures around the Atotsugawa fault system in central Japan, using arrivaltime data from a dense temporary seismograph network conducted by the Japanese University group. The primary results of this study are as follows:

1. A very low-velocity anomaly is imaged locally along the Atotsugawa fault system at a depth of $25 \mathrm{~km}$. The lateral extent of the anomaly is $20-30 \mathrm{~km}$ across the fault, and seismic velocities are 10-13\% lower than those of assumed host rocks (pyroxene amphibolite and hornblende-pyroxene gabbro). Considering the existence of a low-velocity anomaly of $6-9 \%$ with a width of $\sim 100 \mathrm{~km}$ beneath the NKTZ, we propose that a hierarchical structure of low-velocity anomalies has developed around the Atotsugawa fault system. Volume fractions of $\mathrm{H}_{2} \mathrm{O}$ beneath the Atotsugawa fault are estimated to be 3-4 times larger than beneath the NKTZ. A water-weakened lower crust probably plays an important role in the stress accumulation process along the fault plane.

2. At both ends of the Atotsugawa fault system where active volcanoes are formed, seismic velocities are very low in the entire crust. The low-velocity anomaly immediately beneath active volcanoes is explained by the existence of partial melting with fractions of $1-5 \%$ in the lower crust, and can be attributed to aqueous uids with smaller-scale partial melting in the upper crust.

3. Seismic activity along the Atotsugawa fault is very high in the western and eastern sections where $P$ and $S$-wave velocities are higher than $6.0 \mathrm{~km} / \mathrm{s}$ and $3.5 \mathrm{~km} / \mathrm{s}$, respectively. We reveal a laterally-isolated low-velocity zone at a depth of $10 \mathrm{~km}$ in the central section of the Atotsugawa fault where seismic activity is very low and creeplike movements are observed at the surface. Because the seismic activity is deepest in the central section, we infer that aqueous uids with lower temperatures are concentrated there and, consequently, that deformation there is partially anelastic.

This study illustrates major features of the complex velocity structure around the Atotsugawa fault and discusses their relationship to seismic activity along the fault. Our results allow the development of a better model of the deep crustal structure of the fault system. Further work could involve quantitative interpretation of the obtained velocity structures in detail together with other geophysical observations such as seismic attenuation, shear-wave splitting, and electrical conductivity to provide more realistic constraints on numerical simulations of stress accumulation of the Atotsugawa fault system as well as the NKTZ.

Acknowledgments. We thank D. Zhao for providing us with tomographic codes, and A. Hasegawa and T. Matsuzawa for fruitful discussions. We used the uni ed earthquake catalog compiled by the Japan Meteorological Agency (JMA) and seismic data from the National Research Institute for Earth Science and Disaster Prevention, Hokkaido University, Hirosaki University, Tohoku University, University of Tokyo, Nagoya University, Kyoto University, Kochi University, Kyushu University, Kagoshima University, National Institute of Advanced Industrial Science and Technology, the Tokyo Metropolitan Government, the Shizuoka Prefectural Government, the Kanagawa Prefectural Government, the City of Yokohama, the Japan Marine Science and Technology Center, and the JMA. All of the gures in this paper were plotted using GMT (Wessel and Smith, 1998). Constructive reviews by Martin Reyners and an anonymous reviewer improved the manuscript. This study was supported by the Ministry of Education, Culture, Sports, Science and Technology (MEXT) of Japan, under its Observation and Research Program for Prediction of Earthquakes and Volcanic Eruptions.

\section{References}

Geographical Survey Institute, Crustal movements in the Chubu and Hokuriku districts, Rep. Coord. Comm. Earthquake Predict. Jpn., 57, 520-524, 1997 (in Japanese).

Goto, T., H. Wada, N. Ohshiman, and N. Sumitomo, Resistivity structure of a seismic gap along the Atotsugawa fault, Japan, Earth Planet. Sci. Lett., 148, 55-72, 2005.

Hirose, F., J. Nakajima, and A. Hasegawa, Three-dimensional velocity structure in southwestern Japan and con guration of the Philippine Sea slab estimated by double-difference tomography, J. Seismol. Soc. Jpn. 2, 60, 1-20, 2007 (in Japanese with English abstract).

Hirose, F., J. Nakajima, and A. Hasegawa, Three-dimensional seismic velocity structure and con guration of the Philippine Sea slab in southwestern Japan estimated by double-difference tomography, J. Geophys. Res., 113, B09315, doi:10.1029/2007JB005274, 2008.

Hirahara, K., Y. Ooi, M. Ando, Y. Hoso, Y. Wada, and T. Ohkura, Dense GPS array observations across the Atotsugawa fault, central Japan, Geophys. Res. Lett., 30(6), 8012, doi:10.1029/2002GL015035, 2003. 
Iidaka, T., Y. Hiramatsu, and The Japanese University Group of the Joint Seismic Observations at NKTZ, Shear-wave splitting analysis of the upper mantle at the Niigata-Kobe Tectonic Zone with the data of the Joint Seismic Observations at NKTZ, Earth Planets Space, 61, 227235,2009

Iio, Y., T. Sagiya, Y. Kobayashi, and I. Shiozaki, Water-weakened lower crust and its role in the concentrated deformation in the Japanese Islands, Earth Planet. Sci. Lett., 203, 245-253, 2002.

Iio, Y., S. Takeshi, and Y. Kobayashi, Origin of the concentrated deformation zone in the Japanese Islands and stress accumulation process of intraplate earthquakes, Earth Planets Space, 56, 831-842, 2004.

Ito, K., H. Wada, S. Ohmi, N. Hirano, and T. Ueno, Seismic activity from routine and temporary observations of earthquakes in the northwest Chubu district, central Japan, in Geodynamics of Atotsugawa Fault System, edited by M. Ando, pp. 45-63, TERRAPUB, Tokyo, 2007.

Jin, A. and K. Aki, High-resolution maps of Coda Q in Japan and their interpretation by the brittle-ductile interaction hypothesis, Earth Planets Space, 57, 403-409, 2005.

Jin, A., C. A. Moya, and M. Ando, Simultaneous determination of site responses and source parameters of small earthquakes along the Atotsugawa faults zone, central Japan, Bull. Seismol. Soc. Am., 90, 1430-1445, 2000.

Kagami, Y. and T. Watanabe, Inference of shallow crustal materials in the Atotsugawa fault area based on measurements of elastic wave velocities, J. Seismol. Soc. Jpn., 61, 99-111, 2009 (in Japanese with English abstract).

Kato, A., E. Kurashimo, N. Hirata, T. Iwasaki, and T. Iidaka, Imaging crustal structure around the western segment of the Atotsugawa fault system, central Japan, Geophys. Res. Lett., 33, L09307, doi:10.1029/ 2006GL025841, 2006.

Kato, A., T. Iidaka, E. Kurashimo, S. Nakagawa, N. Hirata, and T. Iwasaki, Delineation of probable asperities on the Atotsugawa fault, central Japan, using a dense temporary seismic network, Geophys. Res. Lett., 34, L09318, doi:10.1029/2007GL029604, 2007.

Kern, H., S. Gao, Z. Jin, T. Popp, and S. Jin, Petrophysical studies on rocks from the Dabie ultrahigh-pressure (UHP) metamorphic belt, central China: Implications for the composition and delamination of the lower crust, Tectonophysics, 301, 191-215, 1999.

Kimura, J. and T. Yoshida, Magma pluming system beneath Ontake volcanom, central Japan, Island Arc, 8, 1-29, 1999.

Kono, Y., M. Ishikawa, and M. Arima, Laboratory measurements of P- and $\mathrm{S}$-wave velocities in polycrystalline plagioclase and grabbronorite up to $700^{\circ} \mathrm{C}$ and $1 \mathrm{GPa}$ : Implications for the low velocity anomaly in the lower crust, Geophys. Res. Lett., 33, L15314, doi:10.1029/GL026526, 2006.

Matsubara, M., N. Hirata, S. Sakai, and I. Kawasaki, A low velocity zone beneath the Hida mountains derived from dense array observations and tomographic method, Earth Planets Space, 52, 143-154, 2000.

Mikumo, T., H. Wada, and M. Koizumi, Seismotectonics of the Hida region, central Honshu, Japan, Tectonophysics, 147, 95-119, 1988.

Mizoguchi, K., E. Fukuyama, K. Kitamura, M. Takahashi, K. Masuda, and K. Omura, Depth dependent strength of the fault gauge at the Atotsugawa fault, central Japan: A possible mechanism for its creeping motion, Phys. Earth Planet. Inter., 161, 115-125, 2007.

Mizuno, T., H. Ito, Y. Kuwahara, K. Imanishi, and T. Takeda, Spatial variation of shear-wave splitting across an active fault and its implication for stress accumulation mechanism of inland earthquakes: The Atotsugawa fault case, Geophys. Res. Lett., 32, L20305, doi:10.1029/2005GL023875, 2005.

Nakajima, J. and A. Hasegawa, Deep crustal structure along the NiigataKobe Tectonic Zone, Japan: its origin and segmentation, Earth Planets Space, 59, e5-e8, 2007a.

Nakajima, J. and A. Hasegawa, Subduction of the Philippine Sea slab beneath southwestern Japan: its geometry and role on arc magmatism,
J. Geophys. Res., B08306, doi:10.1029/2006JB004770, $2007 \mathrm{~b}$.

Nakajima, J., T. Matsuzawa, A. Hasegawa, and D. Zhao, Threedimensional structure of $\mathrm{Vp}$, Vs and $\mathrm{Vp} / \mathrm{Vs}$ beneath the northeastern Japan arc: Implications for arc magmatism and uids, J. Geophys. Res., 106, 21843-21857, 2001.

Nakajima, J., F. Hirose, and A. Hasegawa, Seismotectonics beneath the Tokyo metropolitan area: Effect of slab-slab contact and overlap on seismicity, J. Geophys. Res., 114, B08309, doi:10.1029/2008JB006101, 2009.

Nakamura, H., H. Iwamori, and J. Kimura, Geochemical evidence for enhanced uid ux due to overlapping subducting slabs, Nature Geosci., 1, 380-384, 2008

Nishigami, K., Properties of seismic scattering along the Atotsugawa fault system, central Japan: Preliminary analysis of the fault heterogeneous structure, in Geodynamics of Atotsugawa Fault System, edited by M. Ando, pp. 79-83, TERRAPUB, Tokyo, 2007.

Nishimoto, S., M. Ishikawa, M. Arima, T. Yoshida, and J. Nakajima, Simultaneous high P-T measurements of ultrasonic compressional and shear wave velocities in Ichino-megata ma c xenoliths: Their bearing on seismic perturbations in lower crust of northeast Japan arc, J. Geophys. Res., 113, B12212, doi:10.1029/2008JB005587, 2008.

Sagiya, T., S. Miyazaki, and T. Tada, Continuous GPS array and presentday crustal deformation of Japan, Pure Appl. Geophys., 157, 23032322, 2000.

Scholz, H. C., Earthquakes and friction laws, Nature, 391, 37-42, 1998.

Seno, T., S. Stein, and A. E. Gripp, A model for the motion of the Philippine Sea plate consistent with NUVEL-1 and geological data, J. Geophys. Res., 98(B10), 17941-17948, 1993.

Shimazaki, K. and Y. Zhao, Dislocation model for strain accumulation in a plate collision zone, Earth Planets Space, 52, 1091-1094, 2000.

Takei, Y., Effect of pore geometry on Vp/Vs: From equilibrium geometry to crack, J. Geophys. Res., 107(B2), 2043, doi:10.1029/2001JB000522, 2002.

Takeuchi, A., H. Ongirad, and T. Akimitsu, Recurrence interval of big earthquakes along the Atotsugawa fault system, central Japan: Results of seismo-geological survey, Geophys. Res. Lett., 30(6), 8011, doi:10.1029/2002GL014957, 2003.

The Japanese University Group of the Joint Seismic Observations at NKTZ, The Japanese university joint seismic observations at the Niigata Kobe tectonic zone, Bull. Earthquake Res. Inst. Univ. Tokyo, 80, 133-147, 2005 (in Japanese with English abstract).

Ujike, O. and R. Mashimo, Preliminary report on the signi cance of magmatic enclaves in adakite genesis at Hakusan volcano, central Japan, $J$. Mineral. Petrol. Sci., 104, 82-85, 2009.

Wada, H., K. Ito, S. Ohmi, and N. Hirano, Observation of earthquakes at the Kamitakara Observatory by a dense network in the Atotsugawa fault area $\sim 36$ year observation and data analyses, Ann. Disas. Prev. Res. Inst. Kyoto Univ., 50, 313-320, 2007 (in Japanese with English abstract).

Wessel, P. and W. H. F. Smith, New, improved version of the Generic Mapping Tools released, Eos Trans. AGU, 79, 579, 1998.

Yamasaki, T. and T. Seno, High strain zone in central Honshu resulting from the viscosity heterogeneities in the crust and mantle, Earth Planet. Sci. Lett., 232, 13-27, 2005.

Zhao, D., A. Hasegawa, and S. Horiuchi, Tomographic imaging of P and $\mathrm{S}$ wave velocity structure beneath northeastern Japan, J. Geophys. Res., 97, 19909-19928, 1992a.

Zhao, D., S. Horiuchi, and A. Hasegawa, Seismic velocity structure of the crust beneath the Japan islands, Tectonophysics, 212, 289-301, 1992b.

J. Nakajima (e-mail: nakajima@aob.gp.tohoku.ac.jp), A. Kato, T. Iwasaki, S. Ohmi, T. Okada, T. Takeda, and The Japanese University Group of the Joint Seismic Observations at NKTZ 